\title{
Butter naturally enriched in cis-9, trans-11 CLA prevents hyperinsulinemia and increases both serum HDL cholesterol and triacylglycerol levels in rats
}

Mariana Macedo de Almeida', Sheila Cristina Potente Dutra Luquetti ${ }^{2}$ Céphora Maria Sabarense², José Otávio do Amaral Corrêa ${ }^{3}$, Larissa Gomes dos Reis ${ }^{3}$, Ellen Paula Santos da Conceição ${ }^{4}$, Patrícia Cristina Lisboa ${ }^{4}$, Egberto Gaspar de Moura ${ }^{4}$, Jacy Gameiro ${ }^{5}$, Marco Antônio Sundfeld da Gama ${ }^{6}$, Fernando César Ferraz Lopes ${ }^{6}$ and Raúl Marcel González Garcia ${ }^{1 *}$

\begin{abstract}
Background: Evidence from in vitro and animal studies indicates that conjugated linoleic acid (CLA) possesses anti-diabetic properties, which appear to be attributed to cis-9, trans-11 CLA, the major CLA isomer in ruminant fat. However, there is a shortage of studies addressing CLA from natural source. The present study aimed to evaluate the effects of butter naturally enriched in cis-9, trans-11 CLA on parameters related to glucose tolerance, insulin sensitivity and dyslipidemia in rats.
\end{abstract}

Methods: Forty male Wistar rats were randomly assigned to the following dietary treatments ( $n=10 /$ group), for 60 days: 1) Normal fat-Soybean oil (NF-So): diet containing 4.0\% soybean oil (SO); 2) High Fat-Control Butter (HF-Cb): diet containing 21.7\% control butter and 2.3\% SO; 3) High Fat-CLA enriched Butter (HF-CLAb): diet containing 21.7\% cis-9, trans-11 CLA-enriched butter and 2.3\% SO; and 4) High fat-Soybean oil (HF-So): diet containing 24.0\% SO. HF-Cb and HF-CLAb diets contained $0.075 \%$ and $0.235 \%$ of cis-9, trans-11 CLA, respectively.

Results: HF-CLAb-fed rats had lower serum insulin levels at fasting than those fed with the HF-Cb diet, while the PPARY protein levels in adipose tissue was increased in HF-CLAb-fed rats compared to HF-Cb-fed rats. Furthermore, R-QUICK was lower in HF-Cb than in NF-So group, while no differences in R-QUICK were observed among NF-So, HF-CLAb and HF-So groups. Serum HDL cholesterol levels were higher in HF-CLAb-fed rats than in those fed NF-So, $\mathrm{HF}-\mathrm{Cb}$ and HF-So diets, as well as higher in NF-So-fed rats than in HF-Cb and HF-So-fed rats. HF-CLAb, HF-Cb and HF-So diets reduced serum LDL cholesterol levels when compared to NF-So, whereas serum triacylglycerol levels were increased in HF-CLAb.

Conclusion: Feeding rats on a high-fat diet containing butter naturally enriched in cis-9, trans-11 CLA prevented hyperinsulinemia and increased HDL cholesterol, which could be associated with higher levels of cis-9, trans-11 CLA, vaccenic acid, oleic acid and lower levels of short and medium-chain saturated fatty acids from butter naturally modified compared to control butter. On the other hand CLA-enriched butter also increased serum triacylglycerol levels, which could be associated with concomitant increases in the content of trans-9 and trans-10 C18:1 isomers in the CLA-enriched butter.

Keywords: High conjugated linoleic acid enriched butter, Functional food, Rats, Insulin sensitivity, Dyslipidemia, Diabetes

\footnotetext{
* Correspondence: raul.garcia@ufjf.edu.br

'Department of Biology, Federal University of Juiz de Fora, Juiz de Fora, Minas Gerais, Brazil

Full list of author information is available at the end of the article
} 


\section{Background}

Diabetes mellitus is an important cause of mortality and morbidity worldwide, with harmful effects on life expectancy and health-care costs [1]. According to the World Health Organization [2], type 2 diabetes comprises $90 \%$ of the total population with diabetes mellitus around the world, and is characterized by the body's ineffective use of insulin. It is projected that the number of people with diabetes mellitus worldwide will rise to 439 million by 2030 [3]. There is compelling evidence that diet plays an important role in the prevention of a number of noncommunicable diseases, including type-2 diabetes [4]. In this context, conjugated linoleic acid (CLA) has attracted considerable attention in the scientific community due to its health-promoting properties reported in a number of in vitro and animal studies [5]. CLA refers to the positional and geometric conjugated dienoic isomers of linoleic acid (C18:2 n-6) [6] which are predominantly found in ruminant fat [7]. Although nearly twenty isomers have been identified in ruminant products [8], $75-90 \%$ of total CLA is represented by cis-9, trans -11 CLA (rumenic acid) [9], whereas the trans-10, cis-12 CLA isomer is normally found in very low concentrations [10].There is some evidence that the antidiabetogenic effects reported in several studies are mediated by rumenic acid [11], the major CLA isomer in ruminant fat.

As dairy products are the major source of CLA in the human diet [7], efforts have been made to increase the milk fat CLA content, which can be achieved by including plant oils in the diet of dairy cows $[12,13]$. Most of the cis-9, trans-11 CLA secreted in milk is synthesized endogenously from trans-11 C18:1 (vaccenic acid) through stearoyl-CoA desaturase enzyme (also known as $\Delta-9$ desaturase). Therefore, milk naturally enriched in cis9, trans-11 CLA is also a rich source of vaccenic acid [14]. Endogenous synthesis of cis-9, trans-11 CLA from C18:1 trans-11 has also been reported in humans [15] and other species $[16,17]$, which further contributes to increasing the cis-9, trans-11 CLA levels in the body tissues. It should also be noted that the concentrations of some minor (e.g. trans-C18:1 isomers other than vaccenic) and major (e.g. medium-chain saturated) fatty acids are also altered in milk fat from cows fed diets supplemented with plant oils [13], which should be taken into account when food sources naturally enriched in CLA are used in a given study.

In light of the potential anti-diabetogenic effects of cis-9, trans-11 CLA observed in previous studies and the shortage of studies addressing CLA from natural source, we investigated the effects of a diet containing butter naturally enriched in cis-9 trans-11 CLA on glucose tolerance, insulin sensitivity and dyslipidemia in Wistar rats.

\section{Results}

Food intake of HF-Cb, HF-CLAb and HF-So diets was $20.76 \%, 19.54 \%$ and $27.60 \%$ lower than NF-So food intake, respectively, while no difference was observed between HF-Cb, HF-CLAb and HF-So (Table 1). The energy intake observed in rats fed with the HF-Cb, HFCLAb and HF-So diets was 15.85\%, 13.95\% and 11.04\% higher than in NF-So-fed rats, respectively, but there was no difference among HF-Cb, HF-CLAb and HF-So (Table 1). No differences in weight gain (expressed as a percentage of initial weight) were observed among treatment groups (Table 1).

The effect of NF-So, HF-Cb, HF-CLAb and HF-So diets on body weight during all experimental period is shown in Figure 1. There were no differences among dietary treatments.

Concerning the carcass chemical composition, no differences in moisture, lipid, protein and ash contents was observed among groups (Table 1). PPAR $\gamma$ protein levels in adipose tissue were decreased by $58.70 \%, 62.35 \%$ and $41 \%$ in HF-Cb-fed rats in comparison to those fed with the NF-So, HF-CLAb and HF-So diets, respectively (Figure 2) (Additional files 1, 2, 3 and 4).

Fasting serum insulin levels increased by $21.73 \%$, $11.60 \%$ and $23.65 \%$ in HF-Cb-fed rats in comparison to those fed with the NF-So, HF-CLAb and HF-So diets, respectively (Figure 3A), whereas there were no differences in glycemia levels among experimental groups (Figure 3B). NEFA and leptin did not differ among dietary treatments (Table 1 ).

HOMA index was unchanged by the dietary treatments (Table 1). However, the HF-Cb group had a lower R-QUICKI index (13.63\%) than NF-So, while no difference was observed among HF-CLAb, HF-So and NF-So groups (Table 1). There were no differences in the area under the OGTT glycemic curve (AUC) among dietary treatments (Table 1). Serum cholesterol levels did not differ between HF-CLAb and NF-So groups, whereas there were no differences between HF-Cb and HF-So (Figure 4A). Serum triacylglycerol levels in HF-CLAb were increased by $58.81 \%, 49.54 \%$ and $131.12 \%$ when compared to NF-So, HF-Cb and HF-So groups, respectively (Figure 4B). Serum levels of HDL cholesterol were increased by $10.08 \%, 23.29 \%$ and $25.76 \%$ in HF-CLAbfed rats as compared to those fed with the NF-So, HF$\mathrm{Cb}$ and HF-So diets, respectively (Figure $4 \mathrm{C}$ ). There was no difference in serum LDL cholesterol levels between rats fed with the HF-Cb and HF-CLAb diets, but values observed in these groups were $39.68 \%$ and $36.88 \%$ lower than in NF-So group, respectively, and $21.05 \%$ and $17.37 \%$ lower than in HF-So, respectively (Figure 4D). There was no difference in the LDL cholesterol:HDL cholesterol ratio between HF-Cb and HF-CLAb groups, and these values were lower than HF-So result. The LDL 
Table 1 Metabolic and serum parameters in Wistar rats fed with control or naturally enriched in cis-9, trans-11 CLA butters for 60 days

\begin{tabular}{|c|c|c|c|c|}
\hline & \multicolumn{4}{|c|}{ Dietary treatments } \\
\hline & NF-So ${ }^{1}$ & $\mathrm{HF}-\mathrm{Cb}^{2}$ & $\mathrm{HF}-\mathrm{CLAb}^{3}$ & HF-So ${ }^{4}$ \\
\hline \multicolumn{5}{|c|}{ Dietary intake and weight gain } \\
\hline Intake (g/day/rat) & $26.45 \pm 1.06$ & $20.96 \pm 0.37^{* * *}$ & $21.33 \pm 0.49^{* * *}$ & $19.15 \pm 0.49^{* * *}$ \\
\hline Intake (Kcal/day/rat) & $63.19 \pm 2.52$ & $73.21 \pm 1.31^{* *}$ & $72.01 \pm 1.67^{* *}$ & $70.17 \pm 1.89^{*}$ \\
\hline Weight gain (\%) & $62.15 \pm 1.90$ & $69.31 \pm 2.13$ & $66.05 \pm 2.41$ & $59.80 \pm 3.32$ \\
\hline \multicolumn{5}{|c|}{ Body composition } \\
\hline Moisture (\%) & $50.10 \pm 1.05$ & $50.03 \pm 0.47$ & $48.19 \pm 0.44$ & $50.83 \pm 1.17$ \\
\hline Lipid (\%) & $29.41 \pm 1.38$ & $28.55 \pm 0.64$ & $31.31 \pm 0.50$ & $27.14 \pm 1.36$ \\
\hline Protein (\%) & $17.76 \pm 0.32$ & $17.60 \pm 0.21$ & $16.96 \pm 0.19$ & $17.57 \pm 0.49$ \\
\hline Ash (\%) & $3.38 \pm 0.05$ & $4.13 \pm 0.09$ & $3.66 \pm 0.28$ & $3.87 \pm 0.38$ \\
\hline \multicolumn{5}{|c|}{ Insulin Sensibility Indexes and AUC } \\
\hline HOMA index & $1.11 \pm 0.02$ & $1.40 \pm 0.10$ & $1.39 \pm 0.16$ & $1.08 \pm 0.05$ \\
\hline R-QUICKI & $0.88 \pm 0.02$ & $0.76 \pm 0.03^{*}$ & $0.82 \pm 0.02$ & $0.81 \pm 0.04$ \\
\hline AUC & $13180 \pm 1505$ & $12330 \pm 1158$ & $14390 \pm 1398$ & $14610 \pm 1021$ \\
\hline \multicolumn{5}{|c|}{ Serum metabolites } \\
\hline NEFA (mmol/L) & $0.375 \pm 0.023$ & $0.325 \pm 0.017$ & $0.354 \pm 0.022$ & $0.294 \pm 0.025$ \\
\hline Leptin (ng/mL) & $2.21 \pm 0.21$ & $2.59 \pm 0.26$ & $2.72 \pm 0.35$ & $1.99 \pm 0.20$ \\
\hline LDL-C $C^{5} / \mathrm{HDL}-\mathrm{C}^{6}$ & $1.42 \pm 0.07$ & $0.93 \pm 0.04^{* * *, \# \#}$ & 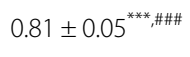 & $1.17 \pm 0.06^{* *}$ \\
\hline non-HDL-C/HDL-C & $1.73 \pm 0.11$ & $1.39 \pm 0.08^{*}$ & $1.33 \pm 0.07^{* *}$ & $1.46 \pm 0.05^{*}$ \\
\hline
\end{tabular}

Data are presented as mean values \pm S.E.M ( $n=10$ rats/group). Statistically significant differences were determined by Anova followed by Newman-Keuls. Asterisk denotes statistically significant differences compared to NF-So $\left({ }^{*} p<0.05,{ }^{* *} p<0.01,{ }^{* * *} p<0.001\right)$ and number sign denotes statistically significant differences compared to HF-So ( ${ }^{\#} p<0.01,{ }^{\# \# \# p<0.001) . ~}{ }^{1}$ Normal Fat-Soybean oil (NF-So), diet containing $4.0 \%$ soybean oil (SO); ${ }^{2} \mathrm{High}$ Fat-Control Butter (HF-Cb), diet containing $21.7 \%$ control butter and $2.3 \%$ SO; ${ }^{3}$ High CLA Butter (HF-CLAb), diet containing $21.7 \%$ butter naturally enriched in cis-9, trans-11 CLA and $2.3 \%$ SO; ${ }^{4}$ High Fat-Soybean oil (HF-So), diet containing $24.0 \%$ SO.

${ }^{5} \mathrm{LDL}-\mathrm{C}$ : LDL cholesterol; ${ }^{6} \mathrm{HDL}-\mathrm{C}: \mathrm{HDL}$ cholesterol.

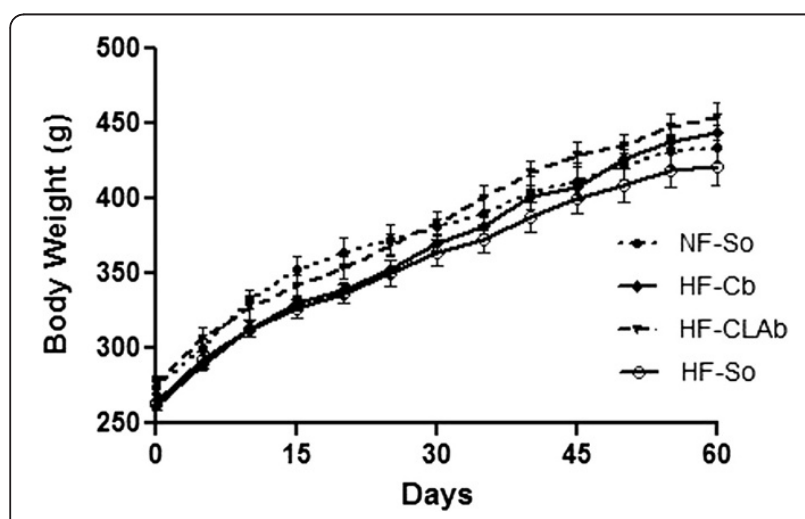

Figure 1 Effect of control or naturally enriched in cis-9, trans-11 CLA butters on body weight. Male Wistar rats fed the following dietary treatments for 60 days: Normal fat-Soybean oil (NF-So): diet containing 4.0\% soybean oil (SO); High Fat-Control Butter (HF-Cb): diet containing 21.7\% control butter and 2.3\% SO; High Fat-CLA enriched Butter (HF-CLAb): diet containing 21.7\% cis-9, trans-11 CLA-enriched butter and 2.3\% SO; High fat-Soybean oil (HF-So): diet containing $24.0 \%$ SO. All data are presented as mean values \pm S.E.M ( $n=10$ rats/group). Statistically significant differences were determined by Anova followed by Newman-Keuls. ${ }^{*} p<0.05$, ${ }^{* *} p<0.01$
cholesterol:HDL cholesterol ratio of high fat diet groups were lower than the value of NF-So (Table 1). There was no difference in the non-HDL cholesterol: HDL cholesterol ratio among HF-Cb, HF-CLAb and HF-So groups, while these values were lower than NFSo result (Table 1).

\section{Discussion}

In recent years, conjugated linoleic acid has received much attention as a dietary supplement [11], however few studies assess the effects of CLA from natural sources on insulin, glucose and serum lipid metabolism. In this paper, we have demonstrated dietary effects of cis-9, trans-11 CLA-enriched butter in 60-day-old Wistar rats on feed intake, body composition, insulin and glucose metabolism as well as dyslipidemia.

In this study, there were no differences in dietary intake among rats fed with cis-9, trans-11 CLA-enriched butter, control butter or high fat-soybean oil. HF-Cb, HF-CLAb or HF-So-fed rats adapted to the higher energy density of these diets by reducing their daily food intake compared to the NF-So group, as was previously reported [18]. Daily energy intake was higher in $\mathrm{HF}-\mathrm{Cb}$, 


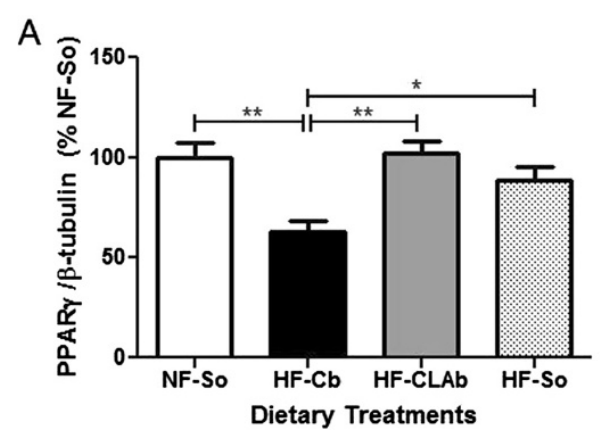

B

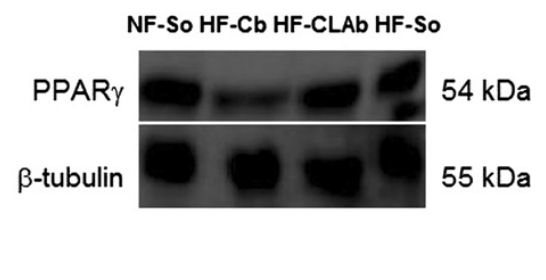

Figure 2 Analysis of PPARy protein level in retroperitoneal adipose tissue. PPARy levels (A) and representative blot for PPARY and $\beta$-tubulin (loading control) (additional Electrophoretic blot files show this in more detail [see Additional files 1, 2, 3 and 4]) (B) of male Wistar rats fed the following dietary treatments for 60 days: Normal fat-Soybean oil (NF-So): diet containing 4.0\% soybean oil (SO); High Fat-Control Butter (HF-Cb): diet containing 21.7\% control butter and 2.3\% SO; High Fat-CLA enriched Butter (HF-CLAb): diet containing 21.7\% cis-9, trans-11 CLA-enriched butter and 2.3\% SO; High fat-Soybean oil (HF-So): diet containing 24.0\% SO. All data are presented as mean values \pm S.E.M ( $n=10$ rats/group). Statistically significant differences were determined by Anova followed by Newman-Keuls. ${ }^{*} p<0.05,{ }^{* *} p<0.01$.

HF-CLAb and HF-So-fed rats than in the NF-So group, which can be attributed to the increased palatability of high fat diets, which is directly related to higher energetic intake [19]. High fat diets are more palatable because fat content is one of the factors that contribute to food palatability [19].

Experiments have shown that PPAR $\gamma$ is the master adipogenic regulator [20] and, interconnected to its role in adipocyte differentiation, PPAR $\gamma$ regulates insulin sensitivity by transcriptionally activating genes involved in insulin signaling, glucose uptake, and fatty acid uptake and storage [21]. HF-CLAb-fed rats presented increased levels of PPARY in adipose tissue compared to $\mathrm{HF}-\mathrm{Cb}$ fed rats, which may be attributed to higher (213.20\%) supply of cis-9, trans-11 CLA from the CLA-enriched butter diet in comparison to the control butter diet. Studies have demonstrated that cis-9, trans-11 CLA increased the expression of PPAR $\gamma$, whose down-regulation may lead to insulin resistance [22]. It was demonstrated that CLA mixed with $0.286 \%$ cis-9, trans-11 CLA increased the mRNA expression of PPAR $\gamma$ in adipose tissue of Wistar rats, which was related to improved insulin sensitivity [23]. Besides, it was shown that depletion of PPARY in adipose tissue causes insulin resistance, since decreased PPARy action in mature adipocytes, leads to reduced expression of key genes required for insulin signaling in adipocytes [24]. It was previously shown that adipocytespecific constitutive activation of PPAR $\gamma$ in mature adipocytes can regulate whole body insulin sensitivity [25].

Therefore, CLA-enriched butter was shown as having action mechanisms PPAR $\gamma$-dependent, up-regulating its expression in adipose tissue, and preventing PPAR $\gamma$ reduction as was observed by a control butter diet.

Rats fed with cis-9, trans-11 CLA-enriched butter had lower fasting serum insulin levels than rats fed with control butter. Therefore HF-CLAb diet prevented the fasting hyperinsulinemia, which is a result potentially beneficial. According to the European Group for the
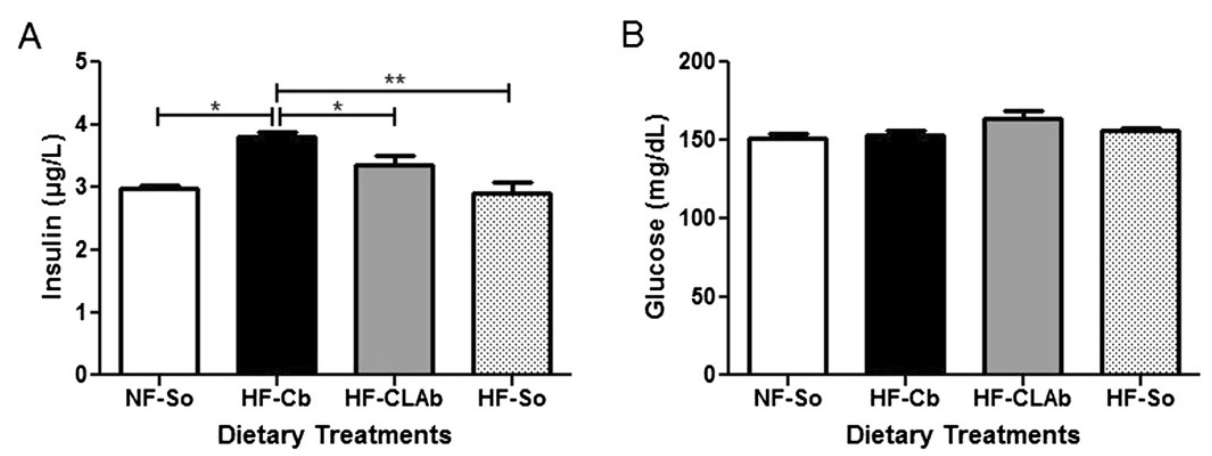

Figure 3 Effects of control or naturally enriched in cis-9, trans-11 CLA butters on serum metabolites. Insulin (A) and glucose (B) of male Wistar rats fed the following dietary treatments for 60 days: Normal fat-Soybean oil (NF-So): diet containing 4.0\% soybean oil (SO); High Fat-Control Butter (HF-Cb): diet containing 21.7\% control butter and 2.3\% SO; High Fat-CLA enriched Butter (HF-CLAb): diet containing $21.7 \%$ cis-9, trans-11 CLA-enriched butter and 2.3\% SO; High fat-Soybean oil (HF-So): diet containing 24.0\% SO. All data are presented as mean values \pm S.E.M ( $n=10$ rats/group). Statistically significant differences were determined by Anova followed by Newman-Keuls. ${ }^{*} p<0.05,{ }^{* *} p<0.01$. 
A

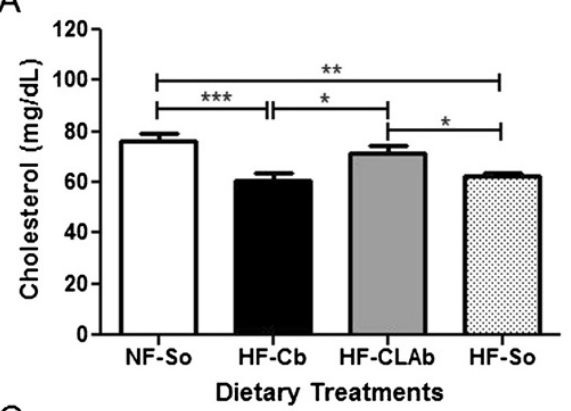

C

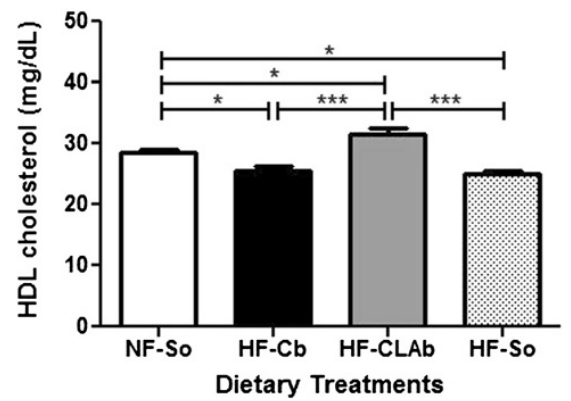

B

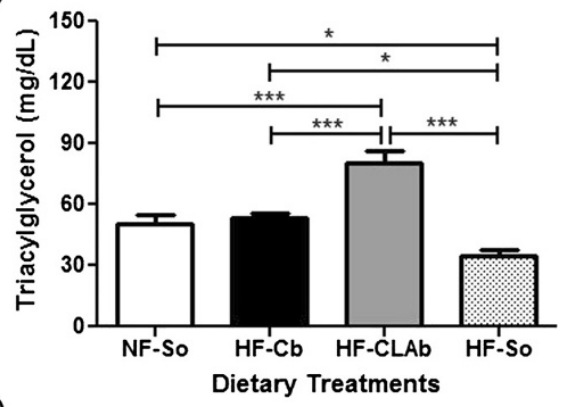

$\mathrm{D}$

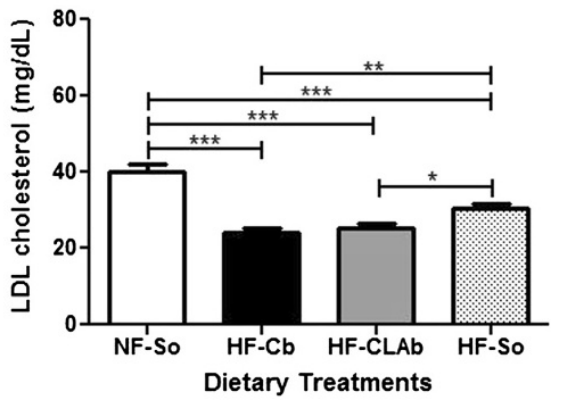

Figure 4 Effects of control or naturally enriched in cis-9, trans-11 CLA butters on lipid serum. Cholesterol (A), triacylglycerol (B), HDL cholesterol (C) LDL cholesterol (D) of male Wistar rats fed the following dietary treatments for 60 days: Normal fat-Soybean oil (NF-So): diet containing 4.0\% soybean oil (SO); High Fat-Control Butter (HF-Cb): diet containing 21.7\% control butter and 2.3\% SO; High Fat-CLA enriched Butter (HF-CLAb): diet containing 21.7\% cis-9, trans-11 CLA-enriched butter and 2.3\% SO; High fat-Soybean oil (HF-So): diet containing 24.0\% SO. All data are presented as mean values \pm S.E.M $(n=10$ rats/group). Statistically significant differences were determined by Anova followed by Newman-Keuls. ${ }^{*} p<0.05,{ }^{* *} p<0.01,{ }^{* * *} p<0.001$.

Study of Insulin Resistance, fasting insulin is the best available simple proxy for insulin resistance, which is defined by presence of fasting hyperinsulinemia [26]. Besides, it was demonstrated that a gradual increase in serum insulin in the fasting state reflects decreased insulin sensitivity [27]. HOMA index did not differ among experimental groups, however R-QUICKI index, which also denotes insulin sensitivity [28], was lower in the HF-Cb group compared to the NF-So group, while there was no difference among the NF-So, HF-CLAb and HFSo groups. Thus, R-QUICKI index shows that control butter diet induces insulin resistance compared to normal fat diet, a condition that was not observed in HFCLAb group and may be associated to PPAR $\gamma$ reduced level in adipose tissue of HF-Cb-fed rats [24].

The beneficial effect of cis-9, trans-11 CLA-enriched butter on fasting insulin level might be due to the higher supply of cis-9, trans-11 CLA from the CLA-enriched butter diet in comparison to the control butter diet. It was previously shown that animals fed with a $0.25 \%$ cis9, trans-11 CLA diet decreased serum insulin concentration at fasting [11]. As observed in Table 1, the concentrations of several fatty acids were also altered in the HF-CLAb diet as compared to the HF-Cb diet. For instance, there was a higher $(269.72 \%)$ supply of vaccenic acid from HF-CLAb diet compared to HF-Cb diet, which contributed to increase the tissue level of cis-9, trans-11 CLA in HF-CLAb-fed rats [16]. Furthermore, there was a lower $(32.06 \%)$ supply of short and mediumchain saturated fatty acids from HF-CLAb diet compared to HF-Cb diet, which could also have contributed to the decreased fasting serum insulin level of the HFCLAb group, since it has been suggested that diets high in saturated fatty acids have effects on hyperinsulinemia [29-31]. Despite the changed parameters of HF-Cb-fed rats, the areas under the curves of oral glucose tolerance tests did not differ among NF-So, HF-Cb, HF-CLAb and HF-So-fed rats, therefore the experimental diets were not responsible for glucose intolerance.

Serum NEFA concentration is a risk factor for type 2 diabetes because the combination of excessive levels of non-esterified fatty acids and glucose leads to decreased insulin secretion, impairments in insulin gene expression and beta-cell death by apoptosis [32]. Previous studies showed that cis-9, trans-11 CLA reduced NEFA levels [11] however, in the present investigation, there were no differences among groups. The lack of an effect of butter enriched in cis-9, trans-11 CLA on NEFA may be attributed to altered bioavailability and bioactivity of cis-9, trans-11 CLA when inserted into the fat butter. A similar hypothesis was developed when it was observed less distinct effect of high-CLA beef compared to synthetic 
CLA on the proteome of insulin-sensitive tissues [33]. Leptin is an adipokine that plays a role in glucose metabolism and insulin sensitivity [34], however in the present study there were no differences among groups. Similarly, it was shown in previous studies that cis-9, trans-11 CLA did not alter leptin levels [11,22,35].

In the present work, serum cholesterol and LDL cholesterol concentrations were not modified by the HFCLAb diet compared to the NF-So and HF-Cb diets, respectively. Similarly, no effects of cis-9, trans-11 CLA on cholesterol and LDL cholesterol levels were also shown previously [36,37]. The high LDL cholesterol concentration in NF-So-fed rats may be due to high levels of carbohydrate (73.39\% of energy) in this diet, since it was demonstrated that when dietary carbohydrate was increased from $50 \%$ to $67 \%$ of energy, the fasting triacylglycerol level rose [38], which is commonly related to increased precursors of LDL cholesterol in the blood, the very-low-density lipoproteins, and consequently increased LDL cholesterol levels [39]. Decreased total cholesterol concentration in HF-Cb or HF-So-fed rats was related to the low HDL cholesterol level in these groups, which is a risk factor for type 2 diabetes mellitus [40].

Increased triacylglycerol levels in HF-CLAb-fed rats may be due to higher (160.37\%) contents of trans-9 and trans-10 C18:1 isomers in the HF-CLAb diet compared to the HF-Cb diet. It has been shown that high intake of trans-9 C18:1 was correlated to increased plasma concentration of triacylglycerol [41] as well as the high intake of trans-10 C18:1 [42]. Concerning the effect of cis-9, trans-11 CLA on the triacylglycerol level, previous studies in animals fed with this CLA isomer did not modify triacylglycerol concentration [43,44]. However, rats fed with the HF-CLAb diet had an increased HDL cholesterol level, which is a potentially beneficial result because it reduces the risk of having a cardiovascular event [45] and HDL cholesterol also has a positive effect on glycemic control [45]. The high level of HDL cholesterol in HF-CLAb-fed rats may be attributed to a higher level of cis-9, trans-11 CLA, as also reported by a previous study [46]. Similarly, it was demonstrated that high CLA enriched clarified butter increased plasma HDL cholesterol in Wistar rats [47]. However, it is possible that the higher supply of oleic acid (cis-9 C18:1) $(27,61 \%)$ from the HF-CLAb diet compared to the HF$\mathrm{Cb}$ diet may also have contributed to increased HDL cholesterol levels, since it has been suggested that oleic acid has effects on increasing HDL cholesterol [48]. Besides, there was a lower (36.91\%) supply of lauric (C12:0) and myristic (C14:0) acids from HF-CLAb diet than HF$\mathrm{Cb}$ diet, which could also have contributed to raised HDL cholesterol levels of HF-CLAb group, since it was demonstrated that a lauric and myristic acid-rich diet decreased HDL cholesterol concentration [49]. On the other hand, the HF-CLAb diet had higher (147.82\%) levels of trans-9 C18:1, which has been associated with decreased levels of HDL cholesterol [50]. Therefore, we hypothesized that fatty acids related to increased HDL cholesterol level were capable of acting synergistically, prevailing over negative effects of trans-9 C18:1 isomers on HDL cholesterol levels, resulting in higher concentration of this lipoprotein in HF-CLAb-fed rats. However, concerning the triacylglycerol levels, it has already been demonstrated by a previous study with animals fed with butter naturally enriched in cis-9 trans-11 CLA that this diet had no effect on the plasma concentration of triacylglycerol [14]. Thus, it was possible to hypothesize that the higher contents of trans-9 and trans-10 C18:1 isomers in the HF-CLAb diet prevailed over the absence of cis-9 trans-11 CLA effects on triacylglycerol levels, resulting in a higher concentration of triacylglycerol in HF-CLAb-fed rats.

\section{Conclusion}

In conclusion, the present investigation suggests that a 60 day feeding of a diet containing butter naturally enriched in cis-9, trans-11 CLA to 60-day-old male Wistar rats has effects on insulin, HDL cholesterol and triacylglycerol metabolism. Cis-9, trans-11 CLA-enriched butter significantly raised serum HDL cholesterol and prevented fasting hyperinsulinemia, which could be attributed to higher levels of cis-9, trans-11 CLA, vaccenic acid, oleic acid and lower levels of short and medium-chain saturated fatty acids from CLA-enriched butter compared to control butter. However, CLA-enriched butter was also found to cause fasting hypertriglyceridemia, which could be associated with concomitant increases in the content of trans-9 and trans-10 C18:1 isomers in the CLA-enriched butter. Additional studies are still needed before conjugated linoleic acid from natural sources can be used in human diets as a functional food to decrease type-2 diabetes risk factors.

\section{Methods}

\section{Ethics statement}

This study was carried out in strict accordance with the recommendations of the Guide for the Care and Use of Laboratory Animals [51]. All procedures with animals were approved by the Ethic Committee on Animal Experimentation of Federal University of Juiz de Fora at Minas Gerais, Brazil, protocol number 054/2012.

\section{Animals}

Forty $(\mathrm{n}=40)$ male Wistar rats (Rattus norvegicus Berkenhout, 1769), 60 days old and weighing 250$300 \mathrm{~g}$, were obtained from the Center of Reproduction Biology of the Federal University of Juiz de Fora, 
Minas Gerais, Brazil. They were kept in a controlled temperature environment $\left(23 \pm 2^{\circ} \mathrm{C}\right)$ with a photoperiod of 12 hours (7 a.m. to 7 p.m. - light and 7 p.m. to 7 a.m. dark). Water and the experimental diets were offered on an ad libitum basis to the animals throughout the study.

\section{Production of experimental butters}

Experimental butters used in the current study were produced at Embrapa Dairy Cattle (Juiz de Fora, Minas Gerais, Brazil). Standard butter and cis-9, trans-11 CLA-enriched butter were produced from milk of cows (Holstein x Gir) fed diets composed of either corn silage and concentrate containing no sunflower oil, or chopped elephant grass and concentrate supplemented with sunflower oil at $4.5 \%$ of diet dry matter, respectively. The butters were produced as described previously [52].

\section{Dietary treatments and experimental design}

After a 7 day acclimatization period in which all animals were fed a commercial chow (Nuvital, Colombo, PR, Brazil), the rats were randomly assigned to four dietary treatments ( $\mathrm{n}=10 /$ group), for 60 days: 1$)$ Normal fatSoybean oil (NF-So): diet containing 4.0\% soybean oil (SO); 2) High Fat-Control Butter (HF-Cb): diet containing $21.7 \%$ control butter and 2.3\% SO; 3) High Fat-CLA enriched Butter (HF-CLAb): diet containing 21.7\% cis-9, trans-11 CLA-enriched butter and 2.3\% SO; and 4) High fat-Soybean oil (HF-So): diet containing 24.0\% SO. SO was included in both HF-Cb and HF-CLAb diets in order to reach the requirements of linoleic and linolenic acids to adults rats [53].

All diets were produced according to the American Institute of Nutrition (AIN-93 M) [53]. Ingredients were carefully mixed in order to obtain a homogeneous mass which was used to produce handmade pellets. The pellets were prepared weekly, purged with nitrogen and stored at $-20^{\circ} \mathrm{C}$ in daily portions in sealed polythene bags to minimize the oxidation of fatty acids. The composition of purified diets is presented in Table 2.

Samples of pellets $(50 \mathrm{~g})$ from each diet were randomly collected and analyzed for chemical composition according to reference methods [54,55]. To determine the fatty acid composition of experimental diets, total lipids were extracted according to Hara and Radin [56] using a 3:2 (vol:vol) mixture of hexane and isopropanol ( $4.5 \mathrm{~mL} / \mathrm{g}$ of pellet) followed by a $67 \mathrm{~g} / \mathrm{L}$ of sodium sulfate solution ( $3 \mathrm{~mL} / \mathrm{g}$ of pellet). Fatty acid methyl esters (FAME) were obtained by base-catalyzed transmethylation using a freshly prepared methylation reagent $(0.4 \mathrm{~mL}$ of $5.4 \mathrm{~mol} / \mathrm{L}$ of sodium methoxide solution $+1.75 \mathrm{~mL}$ of methanol) according to Christie et al., [57] with modifications [58]. The mixture was neutralized with oxalic acid (1 $\mathrm{g}$ of oxalic acid in $30 \mathrm{~mL}$ diethyl ether) and calcium chloride was added to remove methanol residues. The
Table 2 Ingredient composition of experimental diets

\begin{tabular}{|c|c|}
\hline Ingredient & $\%$ of the diet ( $g / 100 \mathrm{~g}$ of diet) \\
\hline Corn starch $^{2}$ & 46.6 or $29.1^{a, b, c, d}$ \\
\hline Dextronized corn starch ${ }^{2}$ & 15.5 \\
\hline Casein $^{1}$ & 14.0 or $17.3^{\mathrm{a}, \mathrm{b}, \mathrm{c}, \mathrm{d}}$ \\
\hline Sucrose ${ }^{1}$ & 10.0 \\
\hline Cellulose $^{2}$ & 5.0 \\
\hline AIN-93 mineral mix ${ }^{1}$ & 3.5 \\
\hline AIN-93 vitamin mix ${ }^{1}$ & 1.0 \\
\hline L-Cystine ${ }^{2}$ & 0.18 \\
\hline Choline bitartrate $^{2}$ & 0.25 \\
\hline tert-Butylhydroquinone ${ }^{1}$ & 0.01 \\
\hline $\mathrm{SO}^{3}$ or Butter ${ }^{4}+\mathrm{SO}^{\mathrm{a}, \mathrm{b}, \mathrm{c}}$ & 4.0 or $24.0^{a, b, c, d}$ \\
\hline
\end{tabular}

1,2 Dietary ingredients were purchased from Rhoster (Araçoiaba da Serra, SP, Brazil) and Farmos (Rio de Janeiro, RJ, Brazil); ${ }^{3}$ Soybean oil (SO); ${ }^{4}$ Control Butter or High CLA Butter. ${ }^{a}$ Normal Fat-Soybean diet consisted of $46.6 \%$ corn starch,

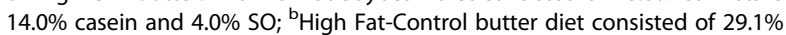
corn starch, $17.3 \%$ casein and $21.7 \%$ Standard Butter $+2.3 \%$ SO; ${ }^{~}$ High Fat-CLA enriched butter diet consisted of $29.1 \%$ corn starch, $17.3 \%$ casein and $21.7 \%$ High CLA Butter $+2.3 \%$ SO; ${ }^{d}$ High Fat-Soybean oil diet consisted of $29.1 \%$ corn starch, $17.3 \%$ casein and $24.0 \%$ SO.

FAME were determined by gas chromatography (model 6890 N; Agilent Technologies Brasil Ltda., Barueri, Brazil) fitted with a flame-ionization detector and equipped with a CP-Sil 88 fused silica capillary column $(100 \mathrm{~m} \times$ $0.25 \mathrm{~mm} \times 0.2 \mu \mathrm{m}$ film thickness; Varian Inc., Mississauga, $\mathrm{ON})$. Operating conditions included injector and detector temperatures both at $250^{\circ} \mathrm{C}, \mathrm{H}_{2}$ as the carrier gas $(1 \mathrm{~mL} /$ $\mathrm{min})$, and for the flame-ionization detector $(35 \mathrm{~mL} / \mathrm{min})$, $\mathrm{N}_{2}$ as the makeup gas $(30 \mathrm{~mL} / \mathrm{min})$, and purified air (286 mL/min). The initial temperature was $45^{\circ} \mathrm{C}$ and held for $4 \mathrm{~min}$, increased by $13^{\circ} \mathrm{C} / \mathrm{min}$ to $175^{\circ} \mathrm{C}$ and held for $27 \mathrm{~min}$, and increased by $4^{\circ} \mathrm{C} / \mathrm{min}$ to $215^{\circ} \mathrm{C}$ and held for 35 min [59]. The FAME were identified by comparison with 4 FAME reference standards (Supelco37 mix \#47885$\mathrm{U}$, linoleic acid isomers mix \#47791, CLA isomers mix \#05632; Sigma-Aldrich, St. Louis, MO, and $\mathrm{Nu}$-Chek GLC-463); minor trans-18:1 isomers were identified according to their elution order reported under the same chromatographic conditions $[59,60]$. The fatty acid composition of experimental diets was expressed as a weight percentage of total fatty acids using theoretical relative response factors described by Wolff et al., [61] (Table 3).

The cis-9, trans-11 CLA content in HF-Cb and HFCLAb diets was calculated as follows: (dry matter content of the diet) $\mathrm{x}$ (fat content $\times$ 0.95) $\mathrm{x}$ (Concentration of cis-9, trans-11 CLA in $\mathrm{g} / 100 \mathrm{~g}$ of total fatty acids). The 5\% discount on fat content was applied to correct for the glycerol concentration in triacylglycerol molecules [62]. Based on the above-mentioned calculations, the cis-9, trans-11 CLA contents in HF-Cb and HF-CLAb diets were $0.075 \%$ and $0.235 \%$, respectively. However, considering that about $11 \%$ of vaccenic acid (trans-11 C18:1) is 
Table 3 Chemical composition and fatty acid profile of the experimental diets

\begin{tabular}{|c|c|c|c|c|}
\hline & \multicolumn{4}{|c|}{ Dietary treatments } \\
\hline & NF-So ${ }^{2}$ & $\mathrm{HF}-\mathrm{Cb}^{3}$ & $\mathrm{HF}-\mathrm{CLAb}^{4}$ & HF-So ${ }^{5}$ \\
\hline & \multicolumn{4}{|c|}{ Chemical composition,\% of diet dry matter } \\
\hline Dry matter content (\%) & 79.1 & 86.8 & 85.4 & 88.4 \\
\hline Fat & 3.11 & 17.6 & 17.4 & 21.1 \\
\hline Crude protein & 13.1 & 16.0 & 16.2 & 14.8 \\
\hline Ash & 2.76 & 2.98 & 3.09 & 2.95 \\
\hline Neutral Detergent Fiber (NDF) & 2.76 & 3.55 & 3.26 & 3.89 \\
\hline Carbohydrate & 55.4 & 44.8 & 43.4 & 42.7 \\
\hline
\end{tabular}

\begin{tabular}{|c|c|c|c|c|}
\hline Carbohydrate & 55.4 & 44.8 & 43.4 & 42.7 \\
\hline & \multicolumn{4}{|c|}{ Energetic composition } \\
\hline Carbohydrate Energy (\%) & 73.4 & 44.6 & 43.9 & 40.7 \\
\hline Protein Energy (\%) & 17.4 & 15.9 & 16.4 & 14.1 \\
\hline Fat Energy (\%) & 9.35 & 39.5 & 39.6 & 45.2 \\
\hline \multirow[t]{2}{*}{$\mathrm{Kcal} / \mathrm{g}$} & 2.39 & 3.49 & 3.38 & 3.71 \\
\hline & \multicolumn{4}{|c|}{ Fatty acids ( $\mathrm{g} / 100 \mathrm{~g}$ of total fatty acids) } \\
\hline C4:0 & n.d. ${ }^{1}$ & 3.16 & 2.95 & n.d. \\
\hline C5:0 & n.d. & 0.03 & 0.01 & n.d. \\
\hline C6:0 & n.d. & 1.69 & 1.37 & n.d. \\
\hline C7:0 & n.d. & 0.02 & 0.01 & n.d. \\
\hline C8:0 & n.d. & 1.00 & 0.64 & n.d. \\
\hline C9:0 & n.d. & 0.03 & 0.01 & n.d. \\
\hline C10:0 & n.d. & 2.07 & 1.14 & n.d. \\
\hline C10:1 cis-9 & n.d. & 0.26 & 0.12 & n.d. \\
\hline C11:0 & n.d. & 0.02 & 0.01 & n.d. \\
\hline C12:0 & n.d. & 2.37 & 1.25 & n.d. \\
\hline C12:1 cis-9/C13:0 & n.d. & 0.16 & 0.08 & n.d. \\
\hline C14:0 & 0.52 & 8.71 & 5.74 & 0.54 \\
\hline $\mathrm{C} 15: 0$ iso & n.d. & 0.20 & 0.25 & n.d. \\
\hline C15:0 anteiso & n.d. & 0.41 & 0.47 & n.d. \\
\hline C14:1 cis-9 & n.d. & 0.83 & 0.46 & n.d. \\
\hline C15:0 & n.d. & 0.95 & 0.90 & n.d. \\
\hline C16:0 & 11.7 & 29.3 & 19.7 & 11.8 \\
\hline C16:1 trans-9 & n.d. & 0.03 & 0.03 & n.d. \\
\hline $\mathrm{C} 17: 0$ iso & n.d. & 0.32 & 0.51 & n.d. \\
\hline C16:1 cis-9 + C17:0 anteiso & n.d. & 1.51 & 1.16 & n.d. \\
\hline C17:0 & n.d. & 0.49 & 0.51 & n.d. \\
\hline C17:1 cis-9 & n.d. & 0.18 & 0.19 & n.d. \\
\hline C18:0 & 4.25 & 9.02 & 13.9 & 4.23 \\
\hline C18:1 trans-4 & n.d. & 0.02 & 0.07 & n.d. \\
\hline C18:1 trans-5 & n.d. & 0.02 & 0.06 & n.d. \\
\hline C18:1 trans-6/7/8 & n.d. & 0.31 & 0.80 & n.d. \\
\hline C18:1 trans-9 & n.d. & 0.23 & 0.57 & n.d. \\
\hline C18:1 trans-10 & n.d. & 0.30 & 0.81 & n.d. \\
\hline C18:1 trans-11 & n.d. & 1.09 & 4.03 & n.d. \\
\hline C18:1 trans-12 & n.d. & 0.29 & 0.65 & n.d. \\
\hline
\end{tabular}


Table 3 Chemical composition and fatty acid profile of the experimental diets (Continued)

\begin{tabular}{|c|c|c|c|c|}
\hline C18:1 trans-13/14 & n.d. & 0.24 & 0.49 & n.d. \\
\hline C18:1 cis-9/trans-15 & 23.8 & 20.3 & 25.9 & 22.4 \\
\hline Minor cis-C18:1 isomers (c11 + c12+c13) & 1.43 & 0.83 & 1.03 & 1.45 \\
\hline C18:1 trans-16 & n.d. & 0.23 & 0.36 & n.d. \\
\hline C18:1 cis-14 & n.d. & 0.05 & 0.10 & n.d. \\
\hline C19:0/C18:1 cis-15 & n.d. & 0.11 & 0.11 & n.d. \\
\hline C18:2 trans-9 trans-12 & n.d. & 0.01 & 0.01 & n.d. \\
\hline C18:2 cis-9 trans-12 & 0.09 & 0.04 & 0.06 & 0.08 \\
\hline C18:2 trans-9 cis-12 & n.d. & 0.03 & 0.04 & n.d. \\
\hline C18:2 cis-9 cis-12 & 49.5 & 8.04 & 7.15 & 52.4 \\
\hline C20:0 & 0.36 & 0.18 & 0.20 & 0.35 \\
\hline C18:3 cis-6, cis-9 cis-12 & n.d. & 0.02 & 0.01 & n.d. \\
\hline C20:1 cis-11 & n.d. & 0.06 & 0.12 & n.d. \\
\hline C18:3 cis-9 cis-12 cis-15 & 6.16 & 0.96 & 0.89 & 6.58 \\
\hline CLA cis-9 trans- 11 & n.d. & 0.53 & 1.66 & n.d. \\
\hline CLA trans-10 cis- 12 & n.d. & 0.01 & 0.01 & n.d. \\
\hline CLA trans- 11 cis-13 & n.d. & 0.01 & 0.02 & n.d. \\
\hline C21:0 & n.d. & 0.03 & 0.03 & n.d. \\
\hline C20:2 cis-11, cis-14 & n.d. & 0.02 & 0.02 & n.d. \\
\hline C22:0 & 0.41 & 0.11 & 0.13 & 0.30 \\
\hline C20:3 n-6 & n.d. & 0.05 & 0.04 & n.d. \\
\hline$C 20: 4 n-6$ & n.d. & 0.10 & 0.08 & n.d. \\
\hline C23:0 & n.d. & 0.03 & 0.01 & n.d. \\
\hline C20:5 n-3 (EPA) & n.d. & 0.02 & 0.01 & n.d. \\
\hline C24:0 & 0.15 & 0.06 & 0.06 & 0.16 \\
\hline C22:5 n3 (DPA) & n.d. & 0.06 & 0.06 & n.d. \\
\hline C22:6 n-3 (DHA) & n.d. & n.d. & n.d. & n.d. \\
\hline
\end{tabular}

${ }^{1}$ n.d.: not detected; ${ }^{2}$ Normal Fat-Soybean oil (NF-So), diet containing 4.0\% soybean oil (SO); ${ }^{3}$ High Fat-Control Butter (HF-Cb), diet containing $21.7 \%$ control butter and $2.3 \%$ SO; ${ }^{4} \mathrm{High}$ CLA Butter (HF-CLAb), diet containing $21.7 \%$ butter naturally enriched in cis-9, trans-11 CLA and $2.3 \%$ SO; ${ }^{5} \mathrm{High}$ Fat-Soybean oil (HF-So), diet containing $24.0 \%$ SO.

endogenously converted into rumenic acid in rodents [16], the increase expected of cis-9, trans-11 CLA in tissue levels of HF-CLAb-fed rats is approximately 15\% higher than the levels in HF-Cb-fed rats. The rats were provided fresh food $\left(\mathrm{F}_{\mathrm{i}}\right)$ ad libitum daily (between 11 a.m and 12 p.m) and the refusals were weighed the next day $\left(F_{f}\right)$, immediately before the provision of another $F_{i}$. Average food intake (grams/animal) was estimated as follows: $\left(F_{i}-F_{f}\right) / 5$ (number of animals per cage). Individual body weight was measured every 5 days throughout the treatment period. After the treatment period, the rats were fasted for 12 hours (7 a.m. to 7 p.m.) and blood samples collected from a tail nick for glycemic determinations using the glucose oxidase method [63]. Immediately after glycemic determinations, animals were anesthetized with an intraperitoneal injection of a xylazine $(10 \mathrm{mg} / \mathrm{Kg}) / \mathrm{ketamine}$ (90 $\mathrm{mg} / \mathrm{Kg}$ ) solution, and euthanized by total exsanguination. Glycemic determinations were performed prior to anesthesia as it was shown to induce hyperglycemia [64]. After euthanasia, blood samples, adipose tissue samples and carcasses were analyzed for parameters related to insulin sensitivity and dyslipidemia in rats.

\section{Analysis of carcass chemical composition}

The carcasses were eviscerated, sliced, stored at $-80^{\circ} \mathrm{C}$, lyophilized (model Liotop L120; Liobras, São Carlos, Brazil) and minced in a knife-type mill. Carcasses were weighed before and after lyophilization to determine their dry matter contents. Moisture, ash, protein and lipid contents were determined according to reference methods [54]. Protein content was quantified using the Kjeldahl method with Foss equipment (model Kjeltec 8400, Foss, Hillerød, Denmark) and lipid content was determined using the Ankom procedure with an Ankom extractor (model XT10, Ankom Technology, New York, USA). 


\section{Analysis of PPARy protein level by western blot}

Retroperitoneal adipose tissue samples were homogenized in a lysis buffer [Tris-HCl: $50 \mathrm{mM}, \mathrm{pH}$ 7.4, $\mathrm{Na}_{4} \mathrm{P}_{2} \mathrm{O}_{7}$ : $30 \mathrm{mM}$, NP-40: 1\%, Triton (1\%), SDS: 0.1\%, NaCl: $150 \mathrm{mM}$, EDTA: $5 \mathrm{mM}$, NaF: $50 \mathrm{mM}$, plus $\mathrm{Na}_{3} \mathrm{VO}_{4}$ : $1 \mathrm{mM}$ and protease inhibitor cocktail (Roche Diagnostics, Mannheim, DE)] using an Ultra-Turrax homogenizer (IKA Werke, Staufen, DE). After centrifugation $(7500 \times \mathrm{g}$ for $5 \mathrm{~min}$ ), the homogenates were stored at $-20^{\circ} \mathrm{C}$ until SDS-PAGE assay. The total protein content of homogenate was determined by the BCA protein assay kit (Pierce, Illinois, USA). Contents of peroxisome proliferatoractivated receptor (PPAR) $\gamma$ and $\beta$-tubulin (loading control) proteins in the retroperitoneal adipose tissue samples were evaluated by incubating monoclonal primary antibodies (anti-PPAR $\gamma$ and anti- $\beta$-tubulin; 1:1000; from Abcam, Cambridge, UK) overnight at $4^{\circ} \mathrm{C}$, followed by proper secondary antibody (1 hour; 1:7000 antibody from Sigma-Aldrich Co., Missouri, USA) and streptavidin (1 hour; 1:7000; Zymed, California, USA) incubation. The protein bands were visualized by chemiluminescence with Kit ECL Plus (GE Healthcare Life Sciences, Buckinghamshire, UK) followed by exposure in the ImageQuant $^{\mathrm{TM}}$ LAS 500 (GE Healthcare Life Sciences). Area and density of the bands were quantified by Image J software (Media Cybernetics, Maryland, USA). The results were normalized by $\beta$-tubulin content and expressed as relative (\%) to NF-So group.

\section{Serum metabolites}

Blood samples were collected from euthanized animals by cardiac puncture and centrifuged $(5714 \times \mathrm{g}$ for $5 \mathrm{~min}$ ) for serum separation. Serum insulin levels were determined using a rat insulin ELISA kit (Mercodia, Uppsala, Sweden). Serum non-esterified fatty acids (NEFA) levels were analyzed using a colorimetric kit (Randox Laboratories, Antrim, United Kingdom), while leptin was analyzed using a Leptin ELISA kit (R\&D Systems, Minneapolis, USA). Serum levels of cholesterol, triacylglycerol, HDL cholesterol and LDL cholesterol were determined by colorimetry using the BT 3000 equipment from Wiener laboratories.

\section{HOMA and R-QUICKI}

Homeostatic Model Assessment (HOMA) index was calculated as follows: [fasting insulin $(\mathrm{ng} / \mathrm{ml}) \times$ fasting glucose $(\mathrm{mM})] / 22.5$. A high HOMA index denotes low insulin sensitivity [65], although it should be acknowledged that the HOMA model has not been validated for use in animal models [66]. The Revised Quantitative Insulin Sensitivity Check Index (R-QUICKI) is another equation to assess insulin sensitivity [28]. This index was calculated as following: [1/log fasting insulin $(\mathrm{mU} / \mathrm{ml})+$ log fasting glucose $(\mathrm{mg} / \mathrm{dl})+\log$ NEFA (mmol/l)] [28]

\section{Oral glucose tolerance test (OGTT)}

After 55 days on the experimental diets, the rats were fasted for 12 hours (7 a.m. to 7 p.m) and received a 50\% glucose solution ( $2 \mathrm{~g} / \mathrm{kg}$ body weight) by oral gavage [67]. Blood samples were collected from a tail nick for glycemic determinations using the glucose oxidase method [63] at 0, 30, 60, 90, 120 and 240 minutes post gavage. Due to reasons previously described, anesthesia was not used in the OGTT. Changes in blood glucose concentration during the oral glucose tolerance test were evaluated by estimation of the total area under the curve (AUC) calculated as an incremental considering the response from the starting point that was analyzed and using the trapezoidal method [68].

\section{Statistical analysis}

The statistical analyses were performed using Prism 5.0 (GraphPad Software, Inc). Data from different dietary groups were analyzed by one-way ANOVA for overall significance followed by Newman-Keuls's post-hoc tests to identify differences between treatment groups. Results were expressed as means \pm SEM (standard error mean). Treatment effects and differences between means were considered significant when $p<0.05$.

\section{Additional files}

Additional file 1: Complete electrophoretic blot of representative bands of PPAR $\gamma$ level in adipose tissue of Wistar rats. Figure containing complete electrophoretic blot of representative bands of PPARy level shown in Figure 2.

Additional file 2: Complete electrophoretic blot of representative bands of PPARY level in adipose tissue of Wistar rats. Figure containing complete electrophoretic blot of representative bands of PPARY level shown in Figure 2. In this file we indicate the experimental group related to each band.

Additional file 3: Complete electrophoretic blot of representative bands of $\beta$-tubulin (loading control) level in adipose tissue of Wistar rats. Figure containing complete electrophoretic blot of representative bands of $\beta$-tubulin level shown in Figure 2.

Additional file 4: Complete electrophoretic blot of representative bands of $\beta$-tubulin level (loading control) in adipose tissue of Wistar rats. Figure containing complete electrophoretic blot of representative bands of $\beta$-tubulin level shown in Figure 2. In this file we indicate the experimental group related to each band.

\section{Abbreviations}

CLA: Conjugated linoleic acid; NF-So: Normal fat-soybean oil; SO: Soybean oil; HF-Cb: High fat-control butter; HF-CLAb: High fat-CLA enriched butter; HF-So: High fat-soybean oil; FAME: Fatty acid methyl esters; PPARY: Peroxisome proliferator-activated receptor $\gamma_{\text {; }}$ HOMA: Homeostatic model assessment; R-QUICKI: Revised quantitative insulin sensitivity check index; OGTT: Oral glucose tolerance test; AUC: Area under the curve.

\section{Competing interests}

The authors declare that they have no competing interests.

\section{Authors' contributions}

MMA conducted the production of experimental diets, rodent feeding experiments, analyzed data, performed statistical analyses and helped to draft the manuscript. SCPDL and CMS conducted the production of 
experimental diets and helped draft the manuscript. JOAC, LGR, EPSC, PCL, EGM and JG provided technical support, helped to interpret data and draft the manuscript. MASG and FCFL assisted with cow feeding and milk collection, production and analysis of experimental butter and diets and helped to draft the manuscript. RMGG oversaw all aspects of the experiments, helped to interpret data and drafted the manuscript. All authors read and approved the final manuscript.

\section{Acknowledgements}

Authors are thankful to Embrapa Dairy Cattle, Coordination of Improvement of Higher Education Personnel (CAPES), National Counsel of Technological and Scientific Development (CNPq), Foundation for Research Support of the Minas Gerais State (FAPEMIG) and Federal University of Juiz de Fora (UFJF) for the financial grants to carry out this work.

\section{Author details}

'Department of Biology, Federal University of Juiz de Fora, Juiz de Fora, Minas Gerais, Brazil. ${ }^{2}$ Department of Nutrition, Federal University of Juiz de Fora, Juiz de Fora, Minas Gerais, Brazil. ${ }^{3}$ Department of Pharmaceutical Sciences, Federal University of Juiz de Fora, Juiz de Fora, Minas Gerais, Brazil. ${ }^{4}$ Department of Physiological Sciences, Roberto Alcantara Gomes Institute of Biology, State University of Rio de Janeiro, Rio de Janeiro, Brazil. ${ }^{5}$ Department of Parasitology, Microbiology and Immunology, Federal University of Juiz de Fora, Juiz de Fora, Minas Gerais, Brazil. ${ }^{6}$ Embrapa Dairy Cattle, Juiz de Fora, Juiz de Fora, Minas Gerais, Brazil.

Received: 21 July 2014 Accepted: 4 December 2014 Published: 22 December 2014

\section{References}

1. Danaei G, Finucane MM, Lu Y, Singh GM, Cowan MJ, Paciorek CJ, Lin JK, Farzadfar F, Khang Y, Stevens GA, Rao M, Ali MK, Riley LM, Robinson CA, Majid Ezzati M: National, regional, and global trends in fasting plasma glucose and diabetes prevalence since 1980: systematic analysis of health examination surveys and epidemiological studies with 370 country-years and 2.7 million participants. Lancet 2011, 378:31-40.

2. World Health Organization, Diabetes: http://www.who.int/mediacentre/ factsheets/fs312/en/

3. Shaw JE, Sicree RA, Zimmet PZ: Global estimates of the prevalence of diabetes for 2010 and 2030. Diabetes Res Clin Prac 2010, 87:4-14

4. Kaur J: A Comprehensive Review on Metabolic Syndrome. Cardiol Res Pract 2014, 2014 ID 943162: 21 pages.

5. Bhattacharya A, Banu J, Rahman M, Causey J, Fernandes G: Biological effects of conjugated linoleic acids in health and disease. J Nutr Biochem 2006, 17:789-810.

6. Wang YW, Jones PJH: Conjugated linoleic acid and obesity control: efficacy and mechanisms. Int J Obes 2004, 28:941-955.

7. Lawson RE, Moss AR, Givens DI: The role of dairy products in supplying CLA to man's diet: a review. Nutr Res Rev 2001, 14:153-172.

8. Roach JAG, Mossoba MM, Yurawecz MP, Kramer JKG: Chromatographic separation and identification of CLA isomers. Anal Chim Acta 2002, 465:207-226.

9. Bauman DE, Corl BA, Peterson DG: The biology of conjugated linoleic acids in ruminants. In Advances in Conjugated Linoleic Acid Research, Volume Volume 2. Edited by Sébédio JL, Christie WW, Adlof R. Champaign: AOCS Press; 2003:146-173.

10. Piperova LS, Teter BB, Bruckental I, Sampugna J, Mills ST, Yurawecz MP, Fritsche J, Ku K, Erdman RA: Mammary lipogenic enzyme activity, trans fatty acids and conjugated linoleic acids are altered in lactating dairy cows fed a milk fat - depressing diet. J Nutr 2000, 130:2568-2574.

11. Halade GV, Rahman MM, Fernandes G: Differential effects of conjugated linoleic acid isomers in insulin-resistant female. J Nutr Biochem 2010, 21:332-337.

12. Collomb M, Schmid A, Sieber R, Wechsler D, Ryhanen EL: Conjugated linoleic acids in milk fat: Variation and physiological effects. Int Dairy $J$ 2006, 16:1347-1361

13. Chilliard Y, Glasser F, Ferlay A, Bernard L, Rouel J, Doreau M: Diet, rumen biohydrogenation and nutritional quality of cow and goat milk fat. Eur Lipid Sci Tech 2007, 109:828-855.

14. Lock AL, Horne CAM, Bauman DE, Salter AM: Butter Naturally Enriched in Conjugated Linoleic Acid and Vaccenic Acid Alters Tissue Fatty Acids and Improves the Plasma Lipoprotein Profile in Cholesterol-Fed Hamsters. J Nutr 2005, 135:1934-1939.

15. Turpeinen AM, Mutanen M, Aro A, Salminen I, Basu S, Palmquist DL, Griinari $J \mathrm{M}$ : Bioconversion of vaccenic acid to conjugated linoleic acid in humans. Am J Clin Nutr 2002, 76:504-510.

16. Santora JE, Palmquist DL, Roehrig KL: Trans-Vaccenic Acid Is Desaturated to Conjugated Linoleic Acid in Mice. J Nutr 2000, 130:208-215.

17. Corl BA, Barbano DM, Bauman DE, Ip C: cis-9, trans-11 CLA Derived Endogenously from trans-11 18:1 Reduces Cancer Risk in Rats. J Nutr 2003, 133:2893-2900.

18. Tarling EJ, Ryan KJP, Bennett AJ, Salter AM: Effect of dietary conjugated linoleic acid isomers on lipid metabolism in hamsters fed highcarbohydrate and high-fat diets. Br J Nutr 2009, 101:1630-1638.

19. Stubbs RJ, Whybrow S: Energy density, diet composition and palatability: influences on overall food energy intake in humans. Physiol Behav 2004, 81:755-764.

20. Kennedy A, Martinez K, Schmidt S, Mandrup S, Lapoint K, Mcintosh M: Antiobesity Mechanisms of Action of Conjugated Linoleic Acid. J Nutr Biochem 2010, 21:171-179.

21. Brown JM, McIntosh MK: Conjugated Linoleic Acid in Humans: Regulation of Adiposity and Insulin Sensitivity. J Nutr 2003, 133:3041-3046.

22. Brown JM, Boysen MS, Jensen SS, Morrison RF, Storkson J, Lea-Currie R, Pariza M, Mandrup S, McIntosh MK: Isomer-specific regulation of metabolism and PPARY signaling by CLA in human preadipocytes. J Lipid Res 2003, 44:1287-1300.

23. Zhou XR, Sun CH, Liu JR, Zhao D: Dietary conjugated linoleic acid increases PPARc gene expression in adipose tissue of obese rat, and improves insulin resistance. Growth Horm IGF Res 2008, 18:361-368.

24. Floyd ZE, Stephens JM: Controlling a Master Switch of adipocyte development and insulin sensitivity: Covalent Modifications of PPAR Biochim Biophys Acta 1822, 2012:1090-1095.

25. Sugii S, Olson P, Sears DD, Saberi M, Atkins AR, Barish GD, Hong SH, Castro GL, Yin YQ, Nelson MC, Hsiao G, Greaves DR, Downes M, Yu RT, Olefsky JM, Evans RM: PPARgamma activation in adipocytes is sufficient for systemic insulin sensitization. Proc Natl Acad Sci U S A 2009, 106:22504-22509.

26. Balkau B, Charles MA: Comment on the provisional report from the WHO consultation. European Group for the Study of Insulin Resistance (EGIR). Diabet Med 1999, 16:442-443.

27. Lindeberg S, Eliasson M, Lindahl B, Bo Ahrén B: Low Serum Insulin in Traditional Pacific Islanders-The Kitava Study. Metabolism 1999, 48:1216-1219.

28. Perseghin G, Caumo A, Caloni M, Testolin G, Luzi L: Incorporation of the fasting plasma FFA concentration into QUICKI improves its association with insulin sensitivity in nonobese individuals. $J$ Clin Endocrinol Metab 2001, 86:4776-4781.

29. Nardi F, Lipina C, Magill D, Hassan RH, Hajduch E, Gray A, Hundal HS: Enhanced Insulin Sensitivity Associated with Provision of Mono and Polyunsaturated Fatty Acids in Skeletal Muscle Cells Involves Counter Modulation of PP2A. PloS One 2014, 9:e92255.

30. Funaki M: Saturated fatty acids and insulin resistance. J Med Invest 2009, 56:88-92.

31. Solfrizzi V, Frisardi V, Capurso C, D'Introno A, Colacicco AM, Vendemiale G, Capurso A, Panza F: Dietary fatty acids in dementia and predementia syndromes: epidemiological evidence and possible underlying mechanisms. Ageing Res Ver 2009, 9:184-199.

32. Poitout V, Amyot J, Semache M, Zarrouki B, Hagman D, Fontés G: Glucolipotoxicity of the Pancreatic Beta Cell. Biochim Biophys Acta 1801, 2010:289-298

33. Rungapamestry V, McMonagle J, Reynolds C, Rucklidge G, Reid M, Duncan G, Ross K, Horgan G, Toomey S, Moloney AP, Roos B, Roche HM: Inter-organ proteomic analysis reveals insights into the molecular mechanisms underlying the anti-diabetic effects of cis-9, trans-11-conjugated linoleic acid in ob/ob mice. Proteomics 2012, 12:461-476.

34. Blüher M: Adipokines - removing road blocks to obesityand diabetes therapy. Mol Metab 2014, 3:230-240.

35. Martins SV, Lopes PA, Alfaia CM, Rodrigues PO, Alves SP, Pinto RMA, Castro MF, Bessa RJB, Prates JAM: Serum adipokine profile and fatty acid composition of adipose tissues are affected by conjugated linoleic acid and saturated fat diets in obese Zucker rats. Br J Nutr 2009, 103:869-878

36. Moloney F, Toomey S, Noone E, Nugent A, Allan B, Loscher CE, Roche HM: Antidiabetic Effects of cis-9, trans-11-Conjugated Linoleic Acid May Be Mediated via Anti-Inflammatory Effects in White Adipose Tissue. Diabetes 2007, 56:574-582. 
37. Joseph SV, Jacques H, Plourde M, Mitchell PL, McLeod RS, Jones PJH: Conjugated Linoleic Acid Supplementation for 8 Weeks Does Not Affect Body Composition, Lipid Profile, or Safety Biomarkers in Overweight, Hyperlipidemic Men. J Nutr 2011, 141:1286-1291.

38. Parks EJ: Effect of Dietary Carbohydrate on Triglyceride Metabolism in Humans. J Nutr 2001, 131(Suppl):2772-2774.

39. Cox RA, García-Palmieri MR: Cholesterol, Triglycerides, and Associated Lipoproteins. In Clinical Methods: The History, Physical, and Laboratory Examinations. 3rd edition. Edited by Walker HK, Hall WD, Hurst JW. Boston: Butterworths; 1990:153-160.

40. Chen L, Magliano DJ, Zimmet PZ: The worldwide epidemiology of type 2 diabetes mellitus-present and future perspectives. Nat Rev Endocrinol 2012, 8:228-236.

41. Cassagno N, Palos-Pinto A, Costet P, Breilh D, Darmon M, Bérard AM: Low amounts of trans 18: 1 fatty acids elevate plasma triacylglycerols but not cholesterol and alter the cellular defence to oxidative stress in mice. $\mathrm{Br} J$ Nutr 2005, 94:346-352.

42. Anadón A, Martínez-Larrañaga MR, Martínez MA, Ares I, Ramos E, GómezCortés P, Juárez M, De la Fuente MA: Acute oral safety study of dairy fat rich in trans-10 C18:1 versus vaccenic plus conjugated linoleic acid in rats. Food Chem Toxicol 2010, 48:591-598.

43. Liu X, Joseph SV, Wakefield AP, Aukema HM, Jones PJH: High Dose trans-10, cis-12 CLA Increases Lean Body Mass in Hamsters, but Elevates Levels of Plasma Lipids and Liver Enzyme Biomarkers. Lipids 2012, 47:39-46.

44. Bissonauth V, Chouinard Y, Marin J, Leblanc N, Richard D, Jacques H: The effect of $\mathrm{t} 10, \mathrm{c} 12 \mathrm{CLA}$ isomer compared with $\mathrm{c9}, \mathrm{t} 11 \mathrm{CLA}$ isomer on lipid metabolism and body composition in hamsters. J Nutr Biochem 2006, 17:597-603

45. Barter PJ: High Density Lipoprotein: A Therapeutic Target in Type 2 Diabetes. Endocrinol Metab 2013, 28:169-177.

46. Nestel P, Fujii A, Allen T: The cis-9, trans-11 isomer of conjugated linoleic acid (CLA) lowers plasma triglyceride and raises HDL cholesterol concentrations but does not suppress aortic atherosclerosis in diabetic apoE-deficient mice. Atherosclerosis 2006, 189:282-287.

47. Chinnadurai K, Kanwal HK, Tyagi AK, Stanton C, Ross P: High conjugated linoleic acid enriched ghee (clarified butter) increases the antioxidant and antiatherogenic potency in female Wistar rats. Lipids Health Dis 2013, 12:121.

48. Bermudez B, Lopez S, Ortega A, Varela LM, Pacheco YM, Abia R, Muriana FJG: Oleic Acid in Olive Oil: From a Metabolic Framework Toward a Clinical Perspective. Curr Pharm Des 2011, 17:831-843.

49. Khosla P, Hajri T, Pronczuk A, Hayes KC: Decreasing Dietary Lauric and Myristic Acids Improves Plasma Lipids More Favorably Than Decreasing Dietary Palmitic Acid in Rhesus Monkeys Fed AHA Step 1 Type Diets. J Nutr 1997, 127(Suppl):525-530.

50. Filip S, Fink R, Hribar J, Vidrih R: Trans Fatty Acids in Food and Their Influence on Human Health. Food Technol Biotechnol 2010, 48:135-142.

51. National Research Council of the National Academies: Guide for the care and use of laboratory animals. Washington, D.C; 2001.

52. Ortiz-Gonzalez G, Jimenez-Flores R, Bremmer DR, Clark JH, DePeters EJ, Schmidt SJ, Drackley JK: Functional properties of butter oil made from bovine milk with experimentally altered fat composition. J Dairy Sci 2007, 90:5018-5031.

53. Reeves PG, Nielsen FH, Fahey GC: AIN-93 Purified Diets for Laboratory Rodents: Final Report of the American Institute of Nutrition Ad Hoc Writing Committee on the Reformulation of the AIN-76A Rodent Diet. J Nutr 1993, 123:1939-1951.

54. Association of Official Analytical Chemist AOAC: Official Methods of Analysis. EUA; 2000

55. Goering HK, Van Soest PJ: Forage fiber analysis (apparatus, reagents, procedures, and some applications). In Agricultural Research Service United States Department of Agricultre, Handbook number 379. Washington, D.C; 1970. as modified by Mertens DR (1992, Personal Communication).

56. Hara A, Radin NS: Lipid extraction of tissues with a low-toxicity solvent. Anal Biochem 1978, 90:420-426.

57. Christie WW: A simple procedure for the rapid transmethylation of glycerolipids and cholesteryl esters. J Lipid Res 1982, 23:1072-1075.

58. Chouinard PI, Corneau L, Sæbø A, Bauman DE: Milk yield and composition during abomasal infusion of conjugated linoleic acids in dairy cows. J Dairy Sci 1999, 82:2737-2745.
59. Cruz-Hernandez C, Kramer JJ, Kennelly DR, Glimm DR, Sorensen BM, Okine EK, Goonewardene LA, Weselake RJ: Evaluating the Conjugated Linoleic Acid Trans 18:1 Isomers in Milk Fat Dairy Cows Fed Increasing Amounts of Sunflower Oil and a Constant Level of Fish Oil. J Dairy Sci 2007, 90:3786-3801

60. Kramer JKG, Cruz-Hernandez C, Zhou J: Conjugated linoleic acids and octadecenoic acids: Analysis by GC. Eur J Lipid Sci Technol 2001 103:600-609.

61. Wolff RL, Bayard CC, Fabien RJ: Evaluation of sequential methods for the determination of butterfat fatty acid composition with emphasis on trans-18:1 acids. Application to the study of seasonal variations in French butters. J Am Oil Chem Soc 1995, 72:1471-1483.

62. Glasser F, Doreau M, Ferlay A, Chilliard Y: Letter to the editor: Estimation of milk fatty acid yield: A response to Stamey et al. (2010). J Dairy Sci 2010, 93:3406.

63. Bergmeyer HU, Bernt E: Determination of glucose with glucose oxidase and peroxidase. In Methods of Enzymatic Analysis. Edited by Bergmeyer HU. New York: Verlag Chemie; 1974:1205-1215

64. Ayala JE, Samuel VT, Morton GJ, Obici S, Croniger CM, Shulman Gl, Wasserman DH, McGuinness OP: Standard operating procedures for describing and performing metabolic tests of glucose homeostasis in mice. Dis Model Mech 2010, 3:535-539.

65. Wallace TM, Levy JC, Matthews DR: Use and Abuse of HOMA Modeling Diabetes Care 2004, 27:1487-1495.

66. Wallace TM, Levy JC, Matthews DR: An increase in insulin sensitivity and basal beta-cell function in diabetic subjects treated with pioglitazone in a placebocontrolled randomized study. Diabet Med 2004, 21:568-576.

67. Kiss ACl, Woodside B, Felício LF, Anselmo-Franci J, Damasceno DC: Impact of maternal mild hyperglycemia on maternal care and offspring development and behavior of Wistar rats. Physiol Behav 2012, 107:292-300.

68. Tai MM: A mathematical model for the determination of total area under glucose tolerance and other metabolic curves. Diabetes Care 1994, 17:152-154

doi:10.1186/1476-511X-13-200

Cite this article as: de Almeida et al.: Butter naturally enriched in cis-9, trans-11 CLA prevents hyperinsulinemia and increases both serum HDL cholesterol and triacylglycerol levels in rats. Lipids in Health and Disease 2015 13:200

\section{Submit your next manuscript to BioMed Central and take full advantage of:}

- Convenient online submission

- Thorough peer review

- No space constraints or color figure charges

- Immediate publication on acceptance

- Inclusion in PubMed, CAS, Scopus and Google Scholar

- Research which is freely available for redistribution 